\title{
DEVELOPMENT OF WEB BASED HIMALAYAN GLACIER INFORMATION SYSTEM USING OPEN SOURCE
}

\author{
Darshana Rawal ${ }^{\mathrm{a}}$, A.K. Sharma ${ }^{\mathrm{b}}$, AnjanaVyas ${ }^{\mathrm{a}}$ and A.S. Rajawat ${ }^{\mathrm{b}}$ \\ aCEPT University, Ahmedabad. email: rawalnet@yahoo.com, anjanavyas@yahoo.com \\ bSpace Applications Centre, Ahmedabad. email: sharma_arun@sac.isro.gov.in, asrajawat@sac.isro.gov.in
}

\section{Commission IV, WG IV/4}

KEY WORDS: Glacier, Himalaya, Natural Resources, OGC, Information System.

\begin{abstract}
:
Systematic inventory of glaciers is required for a variety of applications needed for the comprehensive development of the Himalayan region such as: a) disaster warning, b) estimation of irrigation potential, c) planning and operation of mini and micro hydroelectric power stations, etc.
\end{abstract}

A systematic inventory of the Himalayan glaciers at 1:50,000 scale was created for Indus, Ganga and Brahmaputra basins using Indian Remote Sensing Satellite data and attempted to modified global standards in GIS environment (Sharma et al, 2013). A robust, userfriendly web-based Himalayan Glacier Information System (HGIS), a first of its kind in the country is developed which facilitates any user to selectively display, query, analyse, compose maps and graphs and print, spatial and aspatial information on glaciers relevant to respective interests.

The HGIS architecture is based on Open Geospatial Consortium (OGC) standards and utilises OpenGeo Suite bundled software comprising of Postgresql (PostGIS), Geoserver, GeoWebCache and GeoExplorer each of those having a different function (Anonymous 2010). The spatial and aspatial glacier data sets were stored in a pre-defined format (Sharma et al, 2008) and imbibed into spatially enabled database (PostGIS), having sophisticated functions for spatial data analysis and query. For publishing the data on web page OGC-compliant services are used.

The HGIS information content comprise of a) glacier inventory maps and b) inventory data sheet. The map displays the glacier morphology features like accumulation zone and ablation (ice exposed and debris covered) zones, snout location, de-glaciated valleys, moraines and glacier lakes. The basin, sub-basin and administrative boundaries form the background. The inventory data sheet attributes for each glacier provides information on glacier Location, Identification, Dimension, Orientation, Elevation, Classification, etc. The spatial map and datasheet are linked by unique glacier identification number (galc_id) which is a key field present in all corresponding glacier related point, polygon or line layers. All the glacier attribute were made amenable to query and analysis by users. HGIS represents a significant step towards mapping and compiling individual glacier level inventory data in spatial form to fill the void in data and information on the status of Glaciers in the Himalaya and Trans-Himalayan Karakoram region. HGIS provides a basis for assessing the glacier inventory data which has applications in studies related to climate change, water resource planning, hydropower site selection and mitigation of glacial lake outburst flood (GLOF) hazards.

\section{INTRODUCTION}

Himalayan Glacier Information System (HGIS) provides baseline information on about 35,000 glaciers of entire Himalaya, Trans Himalaya including Karakoram region distributed in 3 major basins (Indus, Ganges and Brahmaputra basins) sub divided into 55 sub-basins. The glacier information is prepared from Indian remote sensing satellite Resourcesat-I LISS III / AWiFS data of period 2004-07 for all glaciers located in India or outside but contributing to rivers in India. The Western Indus region outside India is mapped using AWiFS data of period 200711 .

Himalayan Glacier Information System represents a significant step towards filling the data and information gap on the status of Glaciers in the Himalayan Region. HGIS provides a basis for assessing information on glaciers, which is important for understanding climate change, water resource planning, and mitigation of glacial lake outburst flood (GLOF) hazards.

The HGIS information content comprise of a) glacier inventory maps and b) glacier inventory data sheet. The glacier inventory map displays the glacier morphology like accumulation zone, ablation zone, both ablation zone ice exposed and debris covered. The other glacier features like snout location, de-glaciated valleys, distribution of moraines and glacier lakes like supra glacier lake and moraine dammed/ peri-glacier lake.

The Inventory data sheet provides information on Glacier Identification Number, Dimension, Orientation, Elevation, Primary Classification, Form, etc. as per global standards.

The HGIS comprise of 4 major functions:

\subsection{Display}

Displays feature for basic layers and selected layers. Some of the basic glacier layers are:

- Basin boundary

- $\quad$ Sub-basin Boundary

- International Boundary

- Glacier outlines (having Glacier Data Sheet attached as attributes)

- Glacier morphology layer

- Glacier snout

- Glacier centreline 


\subsection{Smart Filter}

Smart Filter permits multiple querying on the glacier information within a Basin (Indus, Ganga and Brahmaputra) or any of the 55 Sub-basins:

- $\quad$ Identification number (eight digit e.g. 62P05 027)

- Dimension (Area: Glacier total area, Accumulation area, Ablation area, ice exposed area. Length: Glacier Total length, Ablation length, Mean glacier length and Width: glacier ablation mean width)

- $\quad$ Orientation (Eight direction scale viz. E, W, N, S, NE, NW, SE, SW)

- Elevation (Snout elevation, Snow line elevation, highest elevation, Mean elevation of glacier, glacier lake elevation, etc.)

\subsection{Graph Generation}

The glacier features can be interactively displayed on the monitor and can also be saved as image file. The image file can be printed by using the print icon. Limited map graph composition with facilities for editing title and comments/notes for each map/graph are inbuilt for interactive editing.

\subsection{Map Composition and Printing}

The glacier features can be interactively displayed on the monitor and can also be saved as image file. The image file can be printed by using the print icon. Limited map graph composition with facilities for editing title and comments/notes for each map/graph are inbuilt for interactive editing.

\section{RESEARCH OBJECTIVE}

The objective of this research is to develop a Web-based multidimensional spatial data approach that: 1) is interfaced with GIS for the analysis and visualization of spatial GIS database in vector format; 2) permits the combination of GIS database with multidimensional information 3) allow the user to access the databases via OGC standard using any internet browser.

\section{HGIS ARCHITECTURE}

The HGIS architecture is divided in to two parts one is web server architecture and other is database server architecture.

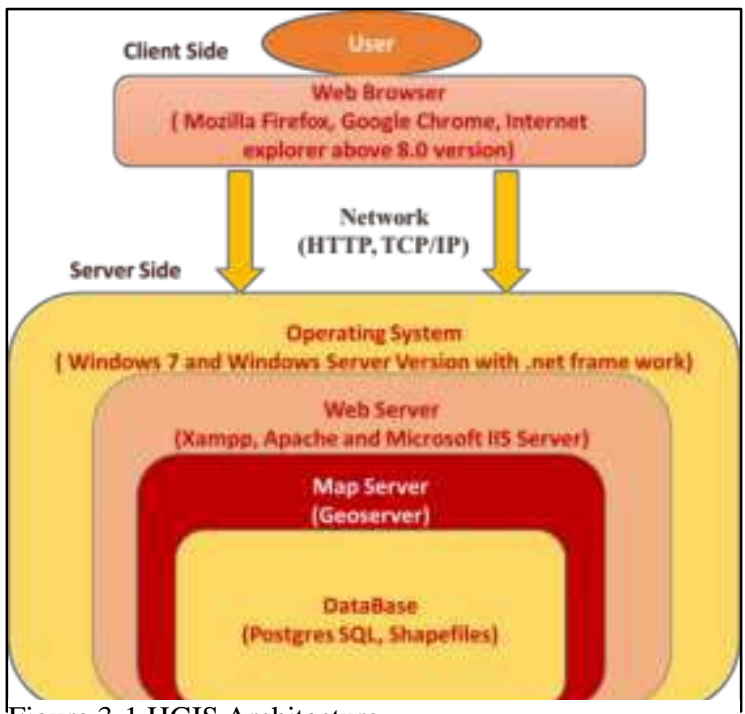

Figure 3-1 HGIS Architecture
The Web GIS is a GIS that uses Web technology. In general Web GIS application have Web browser as a client, for sending the request, and a Web server, for responding to the request. The nonspatial Web applications usually contains only Web server but in case of Web GIS due to voluminous amount of data there is an additional server called data or map server. This server handles the vector data.

The generic layered architecture of Web GIS consists of three layers namely user interface layer, application layer and database layer (Fig. 3.1).

The clients access the system by interacting with the user interface layers that takes the input and shows the output from the system. It involves graphical user interface therefore it must be designed cautiously so that the user can understand it easily. The application layer provides the map visualization functions like panning, zooming etc. It provides the others functions also like querying, etc. (Lu, 2005). The database layer handles the data present at distributed sources.

\subsection{Database Server Architecture}

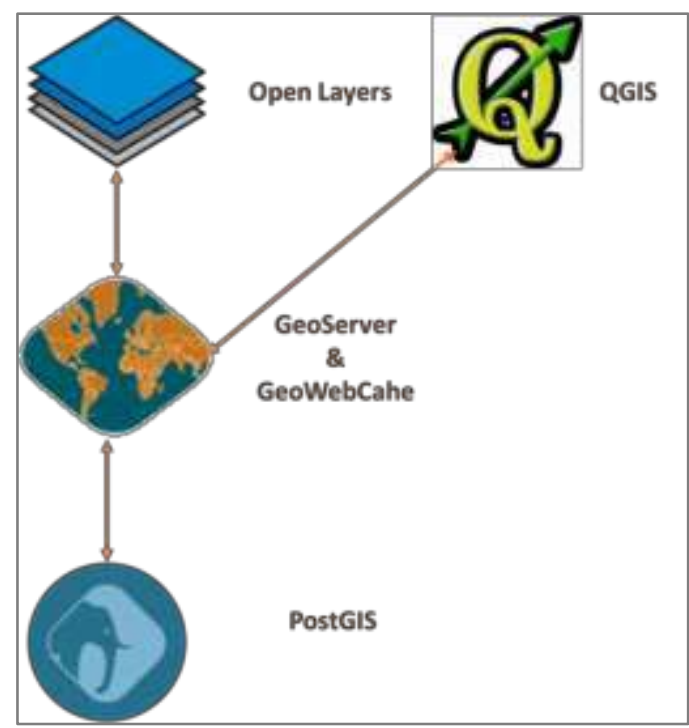

Figure 3-2 Database Server Architecture

\subsection{OPEN SOURCE SOFTWARE (OSS)}

OSS Consortium has made the software available to all According to Free Software Foundation, free software grants four freedoms. These freedoms are to run the program for any purpose, to study how the program works and adapt it to needs, to redistribute copies and the fourth one is to improve the program, and to release improvements to the public. Second and fourth freedom requires source code must be delivered with the software. Following open source software are used in the frameworks:

\subsubsection{Apache Tomcat}

It is an open source Web server and servlet container. Tomcat was the project of Sun Microsystems which was later handed to Apache Foundation. It is widely used for by the applications that are developed using JSP and servlets. Apache Tomcat serves a Web application implemented using the Model-View Controller design, through the well-known frameworks Spring and Apache Tapestry (Fustes et al., 2013). 


\subsubsection{XAMPP Tomcat}

XAMPP stands for Cross-Platform (X), Apache (A), MySQL (M), PHP (P) and Perl (P). It is a simple, lightweight Apache distribution that makes it extremely easy for developers to create a local web server for testing purposes. Everything you need to set up a webserver - server application (Apache), database (MySQL), and scripting language (PHP) - is included in a simple at form, which means it works equally well on Linux, Mac and Windows extractable file.

\subsubsection{OpenGeo Suite}

OpenGeo Suite is a complete geospatial platform for managing data and building maps and applications across web browsers, desktops, and mobile devices. Built on leading open source geospatial software, OpenGeo Suite has a robust and flexible architecture that enables organizations to reliably manage and publish geospatial data.

Manage and store data reliably with PostGIS. Publish maps and data from a variety of formats and sources with GeoServer. Build flexible user interfaces and custom workflows in the browser with Open Layers. Analyze and publish geospatial data on the desktop with QGIS. Access and edit data using open standards from top to bottom, including OGC standards like WMS, WFS, WCS, and others.

\subsubsection{GeoServer}

It is the J2EE realization of Open GIS Web server (Huang and $\mathrm{Xu}, 2011)$. It is an open source platform that supports the OGC standards like Web Map Service (WMS), Web Coverage Service (WCS), Web Feature Service (WFS) and Web Feature Service Transactional protocols. It can work with a large range of data formats like Shapefile, ArcSDE, Oracle Spatial, PostGIS and other spatial formats. It has fully-featured Web administration interface. Role based security can be configures in it. In order to fully utilize the capabilities of GeoServer compatible client software must be used.

Open Layers is a client side software which is widely used with GeoServer. It is an open source JavaScript package based on AJAX technology.

\subsubsection{PostGIS}

PostGIS stores and queries for information about location and mapping and provides spatial objects (geometry, geography, and raster as well as others) for the PostgreSQL object-relational database. It also adds functions, operators, and index enhancements to these spatial types that augment the power of the core PostgreSQL DBMS, making it a fast, feature full, and robust spatial database management system.

Support for common and advanced spatial operations such as geometry creation and conversion, re-projection, buffer, convex hull, generalization, union, and more

- Rendering and importing vector data formats such as Shapefiles KML, GML, GeoJSON, GeoHash and WKT using SQL

- $\quad$ Rendering and importing raster data formats such as GeoTIFF, PNG, JPG, NetCDF, etc.

- Geodetic support for measurements across the globe/dateline

- 3D object support, spatial index, and functions

- Network topology support
- Command-line and graphical tools for flexible management

Open Source, Open Standards PostGIS is open source software, released under the GNU General Public License that implements the Open Geospatial Consortium's "Simple Features for SQL Specification". PostGIS also works well as a data source for GeoServer, which provides services like WMS, WFS, WCS, and WPS.

\subsubsection{QGIS}

QGIS is a cross-platform desktop application for viewing, editing, and analyzing geospatial data from a variety of vector, raster, and database formats.

Viewing of vector and raster data from different formats, including PostGIS, Esri Shapefiles, OGC services, and more Interactive exploration of spatial data, including on-the-fly reprojection Create, edit, and export spatial data.

Perform spatial analysis, including map algebra, terrain analysis, network analysis, and more Publish maps to the internet using OpenGeo Suite Adapt QGIS to your needs with the extensive plugin library.

\section{METHODOLOGY}

The approach was focused on creating and establishing a GIS based robust, state of art user friendly Himalayan Glacier Information System suitable even to the non-initiated users. The approach to HGIS development can be divided in three 1) HGIS web design and development 2) HGIS data base preparation and 3) populating data sets into HGIS.

The HGIS software design and development comprised of review of existing information Systems / Decision Support System (DSS) like Glacier Land Ice Measurements from Space (GLIMS), International Centre for Integrated Mountain Development (ICIMOD) \& Water Resources Information System (WRIS), etc.

\subsection{HGIS data base preparation}

The available information of Glaciers in the form of spatial layers and aspatial tabular form were collected, prepared and compiled as input Glacier Datasets in GIS. This comprised editing for database, correction and standardization as per NRIS/NRDB Standards (Table-1). Preparation of seamless mosaic and organizing data sets at Sub-basin and Basin level in GIS.

Based on the above architecture and with a focus on available data sets and anticipated user requirements the HGIS was developed in three phases to meet the functional requirements:

* Display and primary theme creation

* multi-criteria based selective query and display through custom filters

* Output generation - Outputs like map compositions, tables and graphs as per custom filters selection 
Table 4-1 Data Base Standards

\begin{tabular}{|c|c|c|}
\hline $\begin{array}{l}\text { Sr. } \\
\text { No. }\end{array}$ & Element & Specification \\
\hline \multicolumn{3}{|c|}{ A] Input Specifications } \\
\hline 1 & Location reference & $\begin{array}{l}\text { Latitude- } \\
\text { longitude }\end{array}$ \\
\hline 2 & Scale & $1: 50,000$ \\
\hline 3 & Projection/Map standard & WGS84 \\
\hline \multirow[t]{3}{*}{4} & Thematic Accuracy & \\
\hline & MSU (2mm) & $\begin{array}{l}0.01 \mathrm{sq} \mathrm{km} \text {. or } \\
1.0 \mathrm{ha}\end{array}$ \\
\hline & Mapping Accuracy & $\begin{array}{l}\text { 90/90 } \\
\text { (unverified) }\end{array}$ \\
\hline \multicolumn{3}{|c|}{ B Database Specifications } \\
\hline \multicolumn{3}{|c|}{1 Spatial framework } \\
\hline & Registration scheme & $\begin{array}{l}\text { Lat.-Long. } \\
\text { Graticule } 15 \text { ' x } \\
\text { 15, }\end{array}$ \\
\hline & Projection / Coordinate system & WGS84 / LCC \\
\hline & Coordinate units & Meters \\
\hline \multicolumn{3}{|c|}{2 Accuracy/Error limits } \\
\hline & Registration accuracy (rms) & $6.25 \mathrm{~m}$ \\
\hline & Area & $0.3 \%$ \\
\hline & Weed tolerance & $12.5 \mathrm{~m}$ \\
\hline & Sliver Polygon tolerance & $2500 \mathrm{sq} \mathrm{m}$ \\
\hline
\end{tabular}

\section{RESULTS AND DISCUSSIONS}

The glacier layers mapped as per $15 * 15$ ' latitude-longitude grid and SOI reference no were first mosaicked at sub-basin and basin level to make a single continuous layer. Similarly other layers are also like glacier snout, glacier centrelines are also mosaicked. All layers are organized in GIS. Finally the large volume of spatial and aspatial Primary and Derived datasets on glaciers for entire Ganga Basin are incorporated in HGIS.

The various components of HGIS and interactively obtained results are discussed below:

\subsection{Basic Information}

The HGIS front page GUI (Fig. 5.1) is developed with the basic information on the HGIS, MetaData, Documents /research papers related to Himalayan snow and glacier study, Guidelines used in preparation of data sets, guide for using the HGIS and the most significant component Geo-visualisation for interactively viewing and analysing the glacier data.

\subsection{Geo-Visualization}

The HGIS Geo-Visualization is incorporated with various capabilities.

The HGIS displays the major Indus, Ganga and Brahmaputra Basin boundaries with international boundaries in the back ground and allows users to choose any one major basin for display, query, and graph generation (Fig. 5.2).

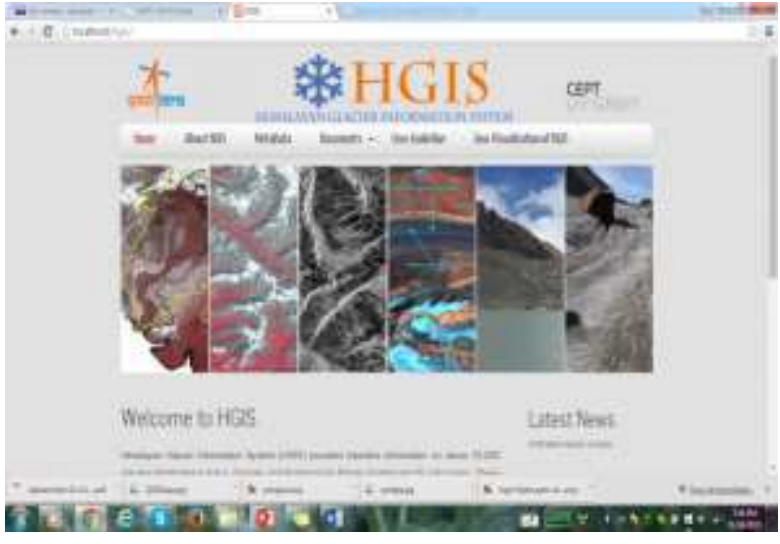

Figure 5.1 Home Page GUI for HGIS

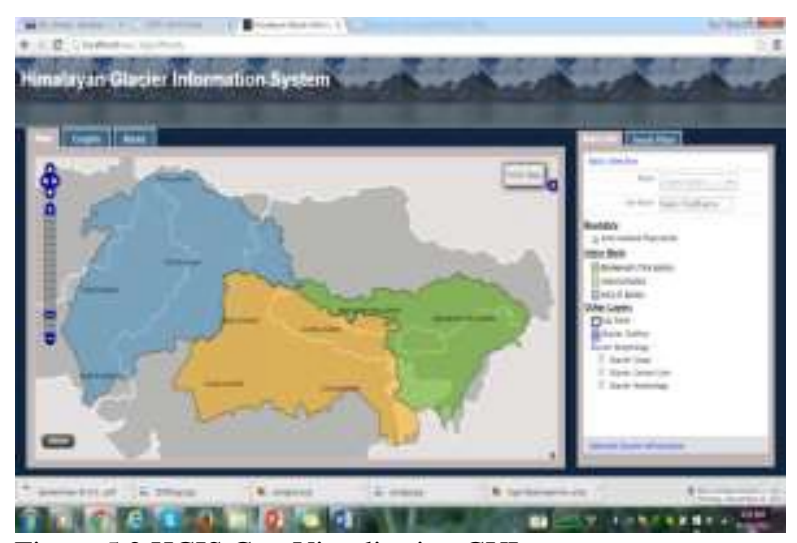

Figure 5.2 HGIS Geo-Visualisation GUI

For any one selected basin (say Ganga Basin) HGIS can display sub-basins with glaciers as a) glacier outlines b) glacier morphology with legend. The glacier morphology features like accumulation area, ablation area-ice exposed, ablation area debris covered, de-glaciated valley, supra glacier lakes and moraine dam / peri-glacial lakes can be displayed. An option for display glacier snout as point location and centreline of glacier is also provided. Only information for the selected sub-basin/s gets displayed Fig. 5-3 and Fig. 5-4.

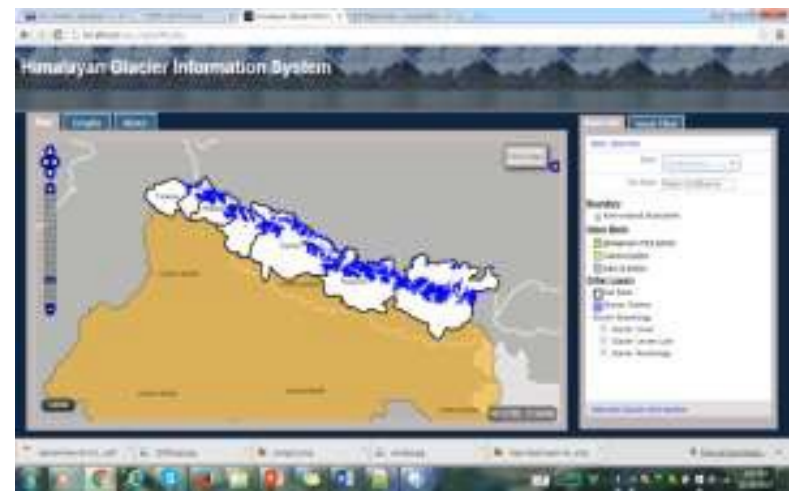

Figure 5-3 Glacier outlines within all sub-basins of Ganga Basin are displayed 
Figure 5-4 HGIS displays information for only the selected Bhagirathi sub-basin

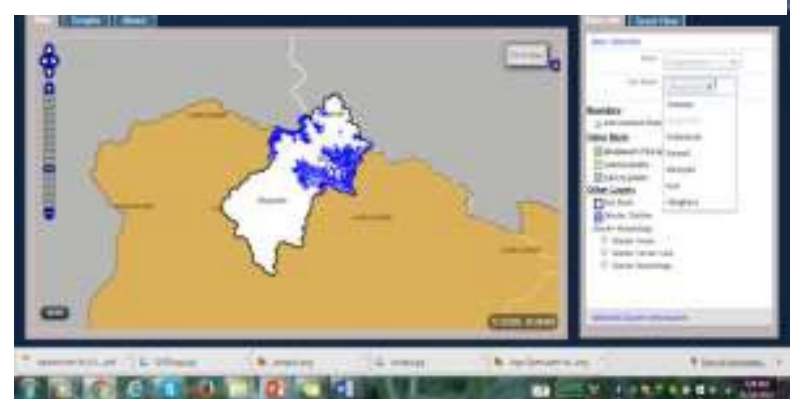

On selecting any individual glacier by using the onscreen cursor the information for that glacier is displayed on the screen (Fig. 55). These 5 parameters/attributes are glacier identification number, glacier total area, maximum elevation and mean elevation.

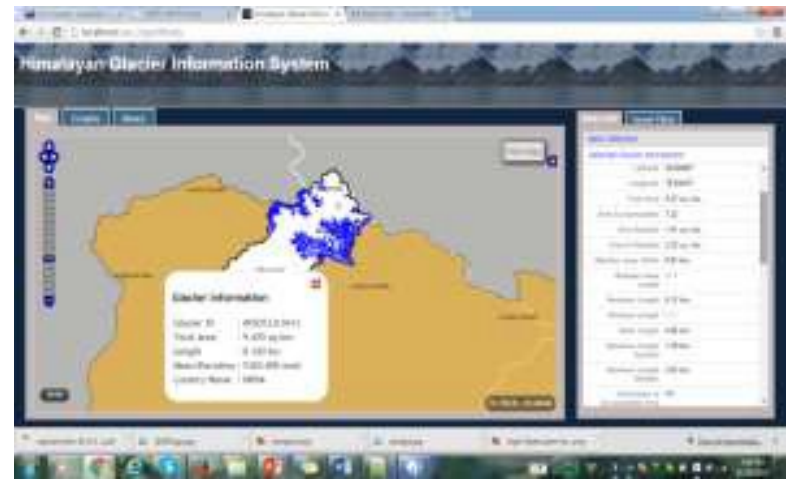

Figure 5-5-Information on one selected glacier- 5 key parameters displayed on screen

Simultaneously the detailed inventory information table for selected glacier is also available for user by activating the "Selected Glacier Information" located at the bottom of the Right Hand Side panel. The scrollable table provides all details for the glacier (Fig. 5-6).

Select any sub-basin(s) and display all glaciers and morphology along with legend in right hand side panel (Fig. 5-7).

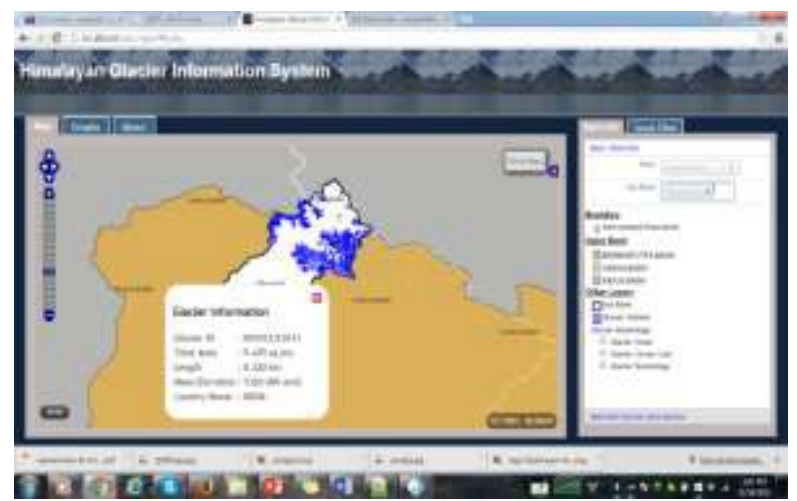

Figure 5-6 Details on the selected glacier in the "Selected Glacier Information” panel in RHS.

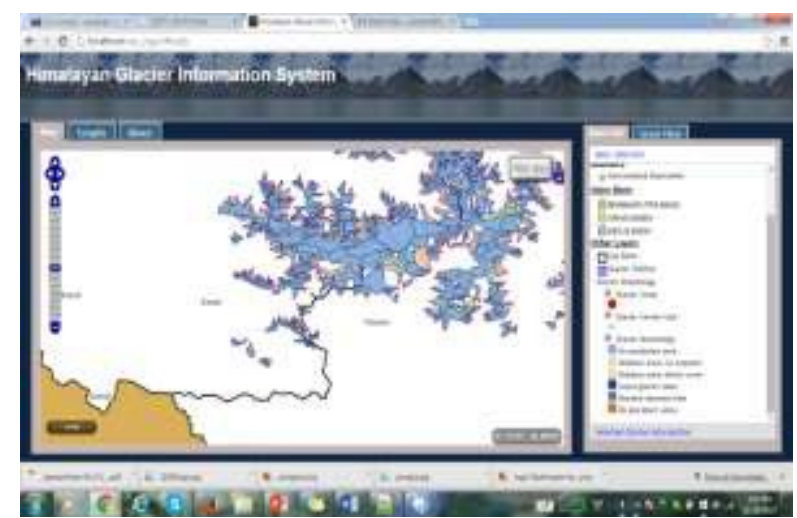

Figure 5-7 Glacier Morphology and legend for all glaciers in selected sub-basins- zoomed in view

Multi-parameter query is applied using "Smart Filter" for identifying and displaying required glaciers according to query (Fig. 5-8)

- $\quad$ one sub-basin /multiple sub-basins

- $\quad$ one parameter / multiple parameter attributes

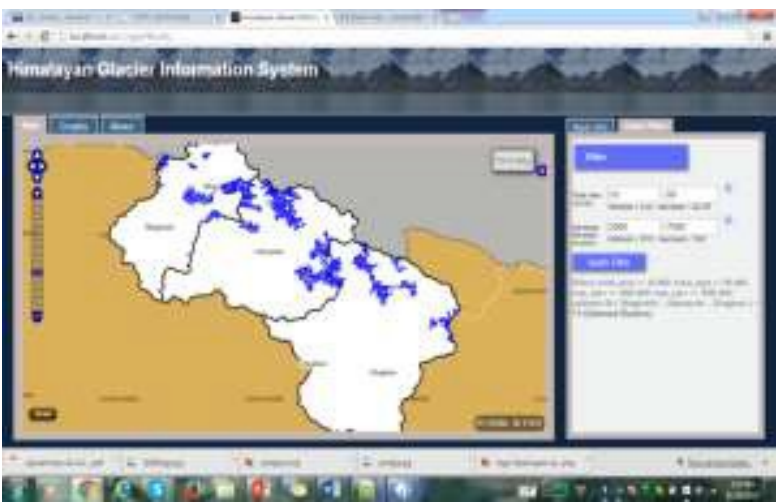

Figure 5-8 Query Results- The glaciers selected through "Smart Filter" query are displayed

Interactively generate graph using the various glacier parameters for sub-basin(s). The parameter and class interval can be decided interactively (Fig. 5-10).

HGIS also has capability of limited editing to the title of the graph / map, comments/ notes and saving it as image file and printing the map and graph using printer settings (Fig. 5-11 and Fig 5-12).

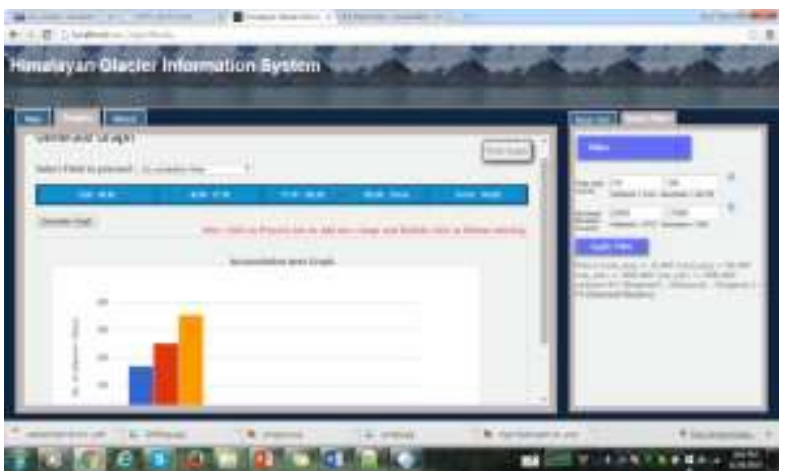

Figure 5-9 interactively generated Graph 


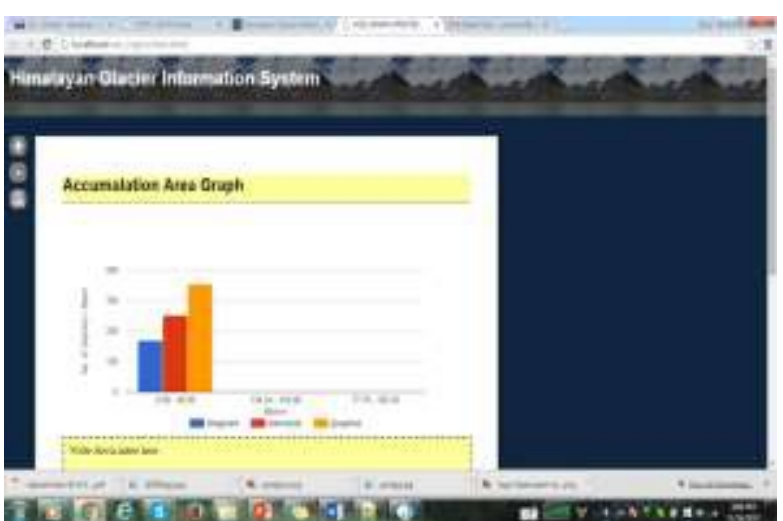

Figure 5-10 Graph composed for saving as image file and printing

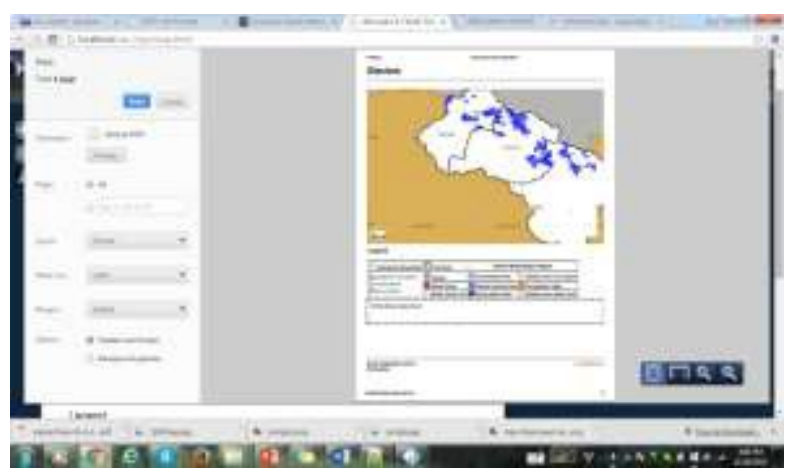

Figure 5-11 map composed for saving as image file and printing

\section{CONCLUSION}

The main purpose of this study was to provide the user with userfriendly tools to visualize both spatial data and associated multidimensional information on the Himalayan Glaciers. The development of the new approach to linking Spatial database strength of Web-based GIS technology, Agencies and organizations that task developing GIS databases, especially applications in natural resource management, can employ this technique to disseminate the various types of collected information to end users having different levels of computer skill. Further research work requires focusing on incorporating more GIS analytical functions and modelling capability to HGIS.

\section{ACKNOWLDAGEMENT}

Authors are thankful the Space Applications Centre to give an opportunity to undertake this research project and keeping the result of this work on open web platform of the institution.

1. https://vedas.sac.gov.in/SAC_HGIS/

2. https://vedas.sac.gov.in/hgis/

\section{REFERENCES}

Anonymous, (2005). Snow and Glacial Studies, Project Execution Document.

2.Anonymous, 2000. NNRMS Node Design and Standards, DOS, ISRO, Bangalore.
3.Anonymous, (2010). OGC(r) Web Feature Service (WFS) Implementation Standard

4. Sharma, A.K., Singh, S.K. and Kulkarni, A.V., (2008) Approach for Himalayan Glacier Inventory using remote sensing and GIS techniques Proc. International Workshop on Snow, Ice, Glacier and Avalanche. Organized by CSRE / IIT-B at Mumbai, pp. 177-188.

5. Sharma, A.K., Singh, S.K. and Kulkarni, A.V. \& Ajai, (2013) Glacier Inventory in Indus, Ganga and Brahmaputra Basins of the Himalaya, National Academy Science Letters ISSN 0250-541X, Volume 36, Number 5 (Natl. Acad. Sci. Lett. (2013) 36:497-505) DOI 10.1007/s40009-013-0167-6

6. http://nsidc.org/data/docs/noa a/g01130_glacier_invent ory/

7. http://boundlessgeo.com/solutions/opengeo-suite/

8. http://www. gli ms.org

9. http://bhuvan. nrsc.gov.in/b huvan_links.p hp

10. http://geoportal.ici mod.org

11. http://www.opengeospatial.org/ogc

12. http://www.indiawris.nrsc. gov.in/GeoVisualiza tion.html 